\title{
Substituent Electronic Effects on the Mulliken Charges of N-(4-Substituted Benzylidene)-1-Phenylmethanamine Oxide Elucidated by DFT Calculations
}

\author{
A. H. Essa ${ }^{*}$ \\ Department of Chemistry, College of Science, University of Basrah, Basrah, Iraq \\ Received 30 October 2009, accepted in final revised form 4 March 2010
}

\begin{abstract}
Calculations based on density functional methods are carried out to investigate the effects of a variety of substituents $\left(\mathrm{NMe}_{2}, \mathrm{OMe}, \mathrm{Me}, \mathrm{F}, \mathrm{H}, \mathrm{Cl}, \mathrm{CN}, \mathrm{NO}_{2}\right)$ on the Mulliken charges $\left(Q_{\mathrm{M}}\right)$ for $\mathrm{C}_{\alpha}$ and $\mathrm{N}$ atoms of $\mathrm{N}$-(4-Substituted benzylidene)-1-phenylmethanamine oxide using Hammett's MSP and Taft's DSP equations. The MSP and DSP correlations give normal substituent effect at $\mathrm{C}_{\alpha}$ and $\mathrm{N}$ atom sites. This can be attributed to extended $\pi$ polarization, which predominates over the localized $\pi$-polarization.
\end{abstract}

Keywords: Correlation analysis; Hammett's and Taft's equations; Nitrone compounds; $\pi$ polarization; Mulliken charges; DFT calculation.

(C) 2010 JSR Publications. ISSN: 2070-0237 (Print); 2070-0245 (Online). All rights reserved.

DOI: $10.3329 /$ jsr.v2i2.3634 J. Sci. Res. 2 (2), 330-336 (2010)

\section{Introduction}

The main merit of the Hammett and Taft's equations,

$$
\log K_{i, \mathrm{X}}-\log K_{i}^{\circ}=\rho_{i} \sigma_{X}
$$

is in its general validity within a given range for practically all substituents (subscript X), and for most well-defined reaction series (subscript $i$ ) [1]. Successful applications are numberless and reported failings are very scarce [2]. This broad success focused attention on the meta and para derivatives of benzene, particularly of benzoic acids as a reference standard. For this reason quantum chemical calculations on these compounds were also started early with different intentions. An important question was whether the linear form of equation 1 can be deduced even from low-level calculations. This was achieved [3] from the linear dependence of $\log K_{i, \mathrm{X}}$ calculated for two reaction series and for variable substituents $X$ at the CNDO level; for para substituents even HMO was sufficient. It was suggested that empirical simplifications made in deriving equation 1 are similar in

*E-mail : alihashemalyunis@yahoo.com 
character as the simplifications involved in the low-level quantum chemical calculations. Similar conclusions was followed from earlier correlations of different quantum chemical indices in one reaction series [4].

In this paper, we focused attention on substituent effects which play a fundamental role in a variety of observed physical chemical phenomena [1] at Mulliken charge $\left(Q_{\mathrm{M}}\right)$ of $\mathrm{N}$-(4-Substituted benzylidene)-1-phenylmethanamine oxide (Scheme I). Applying the density functional theory (DFT) at the B3LYP/ STO-3G level, we expected to obtain more accurate values than in previous work. This series played significant roles in organic chemistry due to their broad utility, serving both as units for many biologically active compounds and as important chiral ligands or chiral auxiliaries for asymmetric synthesis $[5,6]$.

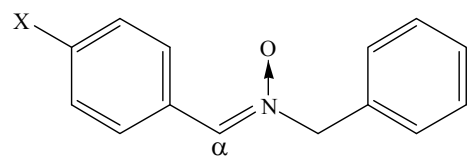

\begin{tabular}{l|cccccccc} 
Comp. No. & $\mathrm{L}$ & 2 & 3 & 4 & 5 & 6 & 7 & 8 \\
\hline Stib. (X) & $\mathrm{NMc}_{2}$ & $\mathrm{OMc}$ & $\mathrm{Mc}$ & F & $\mathrm{H}$ & $\mathrm{Cl}$ & $\mathrm{C}$ & $\mathrm{NO}_{2}$
\end{tabular}

Fig. 1. The structure of $N$-(4-Substituted benzylidene)-1-phenylmethanamine oxide.

\section{Method of Calculation}

The calculations were carried out using the Gaussian 03 program package [7] running on a windows XP workstation with a Pentium IV PC. The $Q_{M}$ for $\mathrm{C}_{\alpha}$ and $\mathrm{N}$ atoms of Parasubstituted phenyl-N-benzylnitrone were done by performing DFT method [8, 9] considering B3LYP exchange- correlation function [10, 11]. STO-3G basis set [12] has been chosen in the DFT calculations. The SCF convergency is set to $0.001 \mathrm{kcal} / \mathrm{mol}$ and the RMS gradient is set to $0.001 \mathrm{kcal} /(\AA \mathrm{mol})$ in the calculations.

Regression analysis were performed by using MINITAB data analysis software release 11.11 standard version [13]. Hammett and Taft constants were taken from the compilation done by Hansch et al. [14].

\section{Results and Discussion}

The present work examines for the first time applicability of mono substituent parameter (MSP) (Hammett's equation) and dual substituent parameter (DSP) (Taft's equation) as descriptors for substituent effects on the Mulliken charge $\left(Q_{M}\right)$ for $\mathrm{C}_{\alpha}$ and $\mathrm{N}$ atoms of $\mathrm{N}$ (4-Substituted benzylidene)-1-phenylmethanamine oxide (Fig. 1). 


\subsection{Hammett's equation}

Table 1 shows the $\sigma$ constants of Hammett's and Taft's models as well as Mulliken charges $\left(Q_{\mathrm{M}}\right)$ for $\mathrm{C}_{\alpha}$ and $\mathrm{N}$ atoms of the studied molecules.

Table 1. Hammett's and Taft's scales and Mulliken charges values for N-(4-Substituted benzylidene)-1-phenylmethanamine oxide

\begin{tabular}{|c|c|c|c|c|c|c|c|c|}
\hline \multirow{2}{*}{ Comp. } & \multirow{2}{*}{ Sub. } & \multicolumn{2}{|c|}{ Hammett } & \multicolumn{3}{|c|}{ Taft } & \multicolumn{2}{|c|}{ Mulliken charges } \\
\hline & & $\sigma_{\mathrm{p}}{ }^{\mathrm{BA}}$ & $\sigma_{\mathrm{p}}^{+}$ & $\sigma_{\mathrm{I}}$ & $\sigma_{R}{ }^{B A}$ & $\sigma_{\mathrm{R}}^{+}$ & $\mathrm{C}_{\alpha}$ & $\mathrm{N}$ \\
\hline 1 & $\mathrm{H}$ & 0.00 & 0.00 & 0.00 & 0.00 & 0.00 & -0.019 & -0.046 \\
\hline 2 & $\mathrm{NMe}_{2}$ & -0.83 & -1.75 & 0.06 & -0.83 & -1.75 & -0.020 & -0.056 \\
\hline 3 & $\mathrm{OMe}$ & -0.27 & -0.74 & 0.27 & -0.61 & -1.02 & -0.020 & -0.051 \\
\hline 4 & $\mathrm{Me}$ & -0.17 & -0.31 & -0.04 & -0.11 & -0.25 & -0.019 & -0.048 \\
\hline 5 & $\mathrm{~F}$ & 0.06 & -0.07 & 0.50 & -0.45 & -0.57 & -0.019 & -0.049 \\
\hline 6 & $\mathrm{Cl}$ & 0.23 & 0.11 & 0.46 & -0.23 & -0.36 & -0.019 & -0.044 \\
\hline 7 & $\mathrm{CN}$ & 0.66 & 0.66 & 0.56 & 0.13 & 0.13 & -0.018 & -0.041 \\
\hline 8 & $\mathrm{NO}_{2}$ & 0.78 & 0.78 & 0.65 & 0.15 & 0.15 & -0.018 & -0.042 \\
\hline
\end{tabular}

MSP analysis (Hammett's model) of the $Q_{M}$ values for both atom sites $\left(\mathrm{C}_{\alpha}\right.$ and $\mathrm{N}$ atoms) of $\mathrm{N}$-(4-Substituted benzylidene)-1-phenylmethanamine oxide are shown in equations 1 and 2 .

$$
\begin{array}{lrl}
Q_{M}(\mathrm{C \alpha})=-0.0191+0.0014 \sigma_{P}{ }^{B A} & \\
n=8 r=0.930 & s=0.205 & F=38.43 \\
Q_{\mathrm{M}(\mathrm{N})}=-0.0461+0.00598 \sigma_{P}{ }^{+} & \\
n=8 r=0.970 & s=0.214 & F=93.44
\end{array}
$$

where $n$ is the number of compounds, $r$ is the correlation coefficient, $s$ is the standard deviation and $F$ is the Fisher ratio.

The empirical Hammett $\sigma$ constants, as expected, exhibited a moderate correlation with the Mulliken charges $\left(Q_{M}\right)$ values. The regression is illustrated in Fig. 2. The $\mathrm{N}$ atom $(r=0.970)$ showed a correlation that was only much better than the $\mathrm{C}_{\alpha}$ atom $(r=0.930)$.
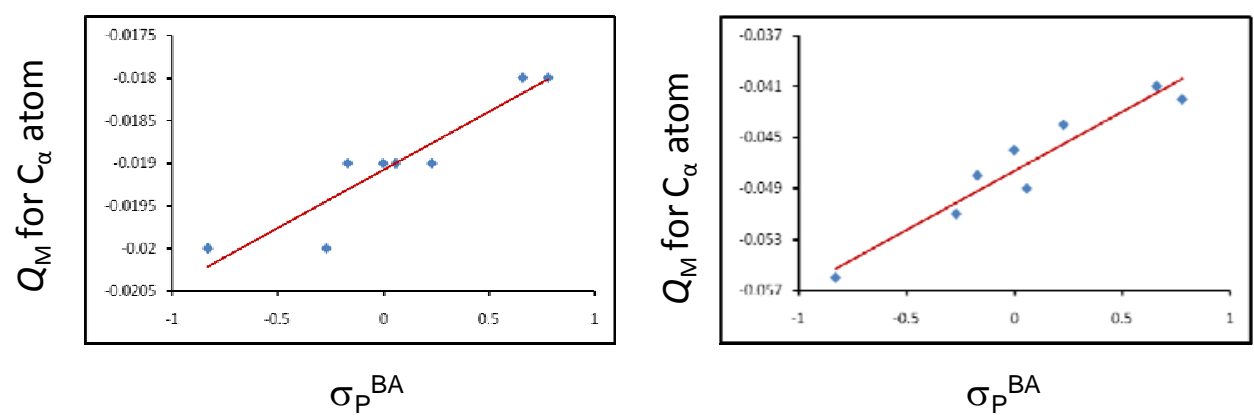

Fig. 2. Correlation between $\sigma_{P}^{B A}$ Hammett constants and Mulliken charges $\left(Q_{\mathrm{M}}\right)$ for $\mathrm{C}_{\alpha}$ and $\mathrm{N}$ atoms. 
The $\mathrm{C} \alpha$ and $\mathrm{N}$ atoms give the same charge, in opposite to the charge sign which alternate in charge sign, similarly to their corresponding $\sigma_{I}$ and $\sigma_{R}$ values. $\sigma_{I}$ and $\sigma_{R}$ are being negative for $\mathrm{C} \alpha$ and indicate a reverse resonance and field effects.

Eqs. 2 and 3 demonstrate the need for a dual parameter correlation in the studied molecules. These equations do not show the ratios of resonance to polar effects at the two investigated atoms.

\subsection{Taft's equation}

The systematic studies of this series by Essa and co-workers in 2009 [15] revealed that the $Q_{M}$ of $\mathrm{N}$ atom are more affected by the substituent than those of $\mathrm{C}_{\alpha}$. This can be attributed to the greater influence of resonance effects at the $\mathrm{N}$ atom, evidenced, for example, by the through conjugation shown in structure 1 .

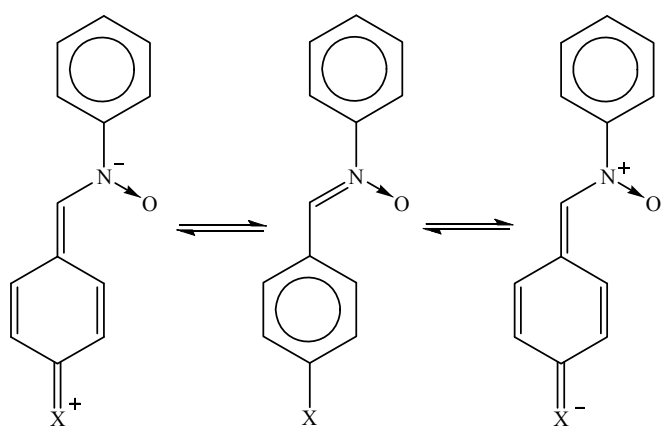

Structure 1

In these canonical structures the $\mathrm{C}_{\alpha}$ site remains relatively unperturbed by resonance effects of $\mathrm{X}$, whereas $\mathrm{N}$ atom obtains excess electron density when $X$ is a donor, and becomes deficient when $X$ is an acceptor.

DSP analysis (Taft's Model) of the Mulliken charges $\left(Q_{\mathrm{M}}\right)$ of the series of compounds (1-8) for $\mathrm{C}_{\alpha}$ and $\mathrm{N}$ atoms show the following results:

$$
\begin{array}{llrr}
Q_{M(C \alpha)}=-0.0189+0.000952 & \sigma_{I}+0.00168 & \sigma_{R}{ }^{B A} \\
n=8 & r=0.966 & s=0.00023 \quad F=34.84 & \lambda=1.765 \\
Q_{M(N)}=-0.0458+0.00522 & \sigma_{I}+0.00629 \sigma_{R}^{+} & \\
n=8 & r=0.972 & s=0.00139 \quad F=42.49 & \lambda=1.205
\end{array}
$$

Generally the Taft's equation gave statistically more significant results than the Hammett's equation for $Q_{M}$ of $\mathrm{C}_{\alpha}$ and $\mathrm{N}$ correlations. Almost identical correlation was found for the $\mathrm{C}_{\alpha}$ and $\mathrm{N}$ atoms.

The resonance effects are the largest at the $\mathrm{N}$ atom site. The preferred resonance scale is ${\sigma_{R}}^{+}$, reflecting the electron demand placed on this site by adjacent phenyl group. The $\rho_{I}$ 
value at $\mathrm{N}$ atom has a positive sign and a magnitude roughly quintuple that of the $\rho_{I}$ value at $\mathrm{C} \alpha$. It is interesting to note that a DSP analysis of ${ }^{13} \mathrm{CNMR}$ substituted chemical shifts (SCS) for the styrene derivatives dose show a differing polar effect [16]. Because of the ability of the nitron group to conjugate with adjacent systems, the electron distribution of the aromatic and nitron systems are closely interrelated and it is therefore reasonable to ask why a positive $\rho_{I}$ value, indicative of polarization as in structure $\mathbf{2 a}$, is consistently observed for the $\mathrm{C}_{\alpha}$ site, when it might be expected that the whole conjugated $\pi$ system should be polarized as a unit, as in structures $\mathbf{2 b}$ or $\mathbf{2 c}$

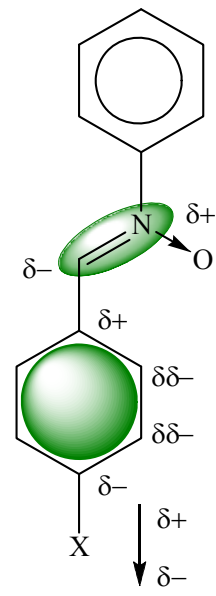

(2a)

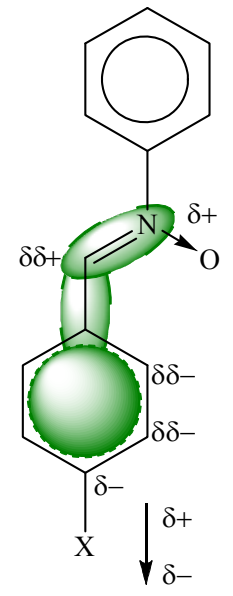

(2b)

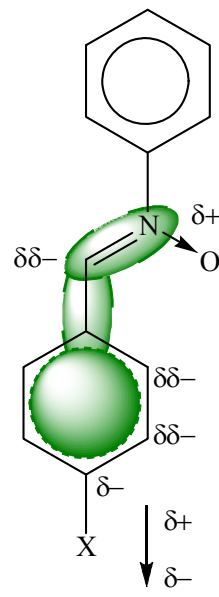

(2c)

Structure 2

The type of polarization, shown in structure $\mathbf{2} \mathbf{b}$ is called extended polarization and results in charge density at $\mathrm{C}_{\alpha}$ having a similar sign to those at the nitrogen atom but of a smaller magnitude. (i.e. small positive $\rho_{I}$ values would be expected). This type of polarization dose indeed occur, but that it does very little to perturb the charge density at $\mathrm{C}_{\alpha}$ site. Most of the charge density change at this site are in fact due to extended polarization structures of the localized $\mathrm{N}-\mathrm{O}$ bond.

It is clear that the $\mathrm{C}_{\alpha}$ and $\mathrm{N}$ atoms are subject to similar substituent effects, the positive sign in $\rho_{I}$ in both atoms are indicative of a normal substituent effect. It indicates that donors induce more charge and acceptors induce less charge. This effect has been noted in a number of side chain systems [17].

The blending constant $\lambda\left(\lambda=\rho_{R} / \rho_{I}\right)$ can categorically classify atoms into two classes. The first class, in which the $\lambda$ is less than one, this means that the substituent resonance effects do not affect the atoms directly. The second class in which the $\lambda$ is more than one, this means that the substituent resonance effects directly affect these atoms. The larger resonance effect in the $\mathrm{C}_{\alpha}$ and $\mathrm{N}$ atom in some systems [18] confirms that some type of secondary resonance effect operates at these sites. It is most likely arises from polarization 
of the side chain $\pi$ system by the diffuse dipole set up in the benzene ring as a result of resonance delocalization by the substituent $X$. There is no secondary resonance in the studied molecules since it is normal to have beta atom in this case nitrogen has positive large $\sigma_{R}$ and the alpha in this case has positive $\sigma_{R}$ but much smaller than the nitrogen. So, there is normal resonance effect.

\section{Conclusions}

In this work, we have investigated the substituent electronic effect on Mulliken charge $\left(Q_{\mathrm{M}}\right)$ of $\mathrm{C}_{\alpha}$ and $\mathrm{N}$ atoms of $\mathrm{N}$-(4-Substituted benzylidene)-1-phenylmethanamine oxide by using Hammett's MSP and Taft's DSP equations, and demonstrate several important points: First, We have shown that the density functional method can be used to calculate quite accurately the substituent effect on the Mulliken charge $\left(Q_{\mathrm{M}}\right)$. Second, it is now documented that single parameter treatment can not adequately describe the trend of substituent electronic effect in $\mathrm{C}_{\alpha}$ and $\mathrm{N}$ atoms especially when we need to know the quantities of inductive and resonance effects. Single parameter treatment contains only one blend of these effects and hence can not, in general, cope with the many cases in which polar and resonance effects are transmitted to different relative extent. Third, the DSP correlations on the Mulliken charge $\left(Q_{\mathrm{M}}\right)$ gave significant improvement over MSP correlations.

\section{References}

1. (a) L.P. Hammett, Physical Organic Chemistry, 2nd ed. (McGraw-Hill, New York, 1970); Chap. 11.9-11.16. (b) O. Exner, Correlation Analysis of Chemical Data (Plenum Press, New York, 1988) Chap. 2.3.

2. K. Waisser, T. Pala' and O. Exner, Collect. Czech.Chem. Commun. 64, 1295, (1999). doi:10.1135/cccc19991295

3. O. Exner, D. Ondrejic `kova' and D. Les `ka, J. Org. Reactivity (Tartu) 16, 285 (1979).

4. (a) J. Koutecky', R. Zahradnı'k and Cÿ1'žek, J. Trans. Faraday Soc. 57, 169 (1961), doi:10.1039/tf9615700169 (b) J. Kuthan, I. Danihel and V. Ska' la, Collect. Czech. Chem. Commun.43, 447 (1978).

5. L. Anderson, M. Cameron, B. G. Gowenlock and I. J. McEwen, J. Chem. Soc., Perkin Trans. II, 243(1992). doi:10.1039/p29920000243

6. Z. A. N. Al-Shamkhani and A. H. Essa, Tetrahedron Letters 48, 5547 (2007). doi:10.1016/j.tetlet.2007.05.146

7. Gaussian 03, Revision C.02, Frisch M. J., Trucks G. W., Schlegel H. B., Scuseria G. E., Robb M. A., Cheeseman J. R., Montgomery J. A., Vreven J.T., Kudin K. N., Burant J. C., Millam J. M., Iyengar S. S., Tomasi J., Barone V., Mennucci B., Cossi M., Scalmani G., Rega N., Petersson G. A., Nakatsuji H., Hada M., Ehara M., Toyota K., Fukuda R., Hasegawa J., Ishida M., Nakajima T., Honda Y., Kitao O., Nakai H., Klene M., Li X., Knox J. E., Hratchian H. P., Cross J. B., Bakken V., Adamo C., Jaramillo J., Gomperts R., Stratmann R. E., Yazyev O., Austin A. J., Cammi R., Pomelli C., Ochterski J. W., Ayala P. Y., Morokuma K., Voth G. A., Salvador P., Dannenberg J. J., Zakrzewski V. G., Dapprich S., Daniels A. D., Strain M. C., Farkas O., Malick D. K., Rabuck A. D., Raghavachari K., Foresman J. B., Ortiz J. V., Cui Q., Baboul A. G., Clifford S., Cioslowski J., Stefanov B. B., Liu G., Liashenko A., Piskorz P., Komaromi I., Martin R. L., Fox D. J., Keith T., Al-Laham M. A., Peng C. Y., Nanayakkara A., 
Challacombe M., Gill P. M. W., Johnson B., Chen W., Wong M. W., Gonzalez C., and Pople J. A., Gaussian, Inc., Wallingford CT, (2004).

8. W. Kohn and L.J. Sham, Phys. Rev. 140, A1133 (1965). doi:10.1103/PhysRev.140.A1133

9. A. H. Essa, Journal of Organometallic Chemistry 692, 4917 (2007). doi:10.1016/j.jorganchem.2007.07.018

10. A.D. Becke, J. Chem. Phys. 98, 5648 (1993). doi:10.1063/1.464913

11. C. Lee, W. Yang and R.G. Parr, Phys. Rev. B 37, 785 (1988). doi:10.1103/PhysRevB.37.785

12. R. Krishnan, J.S. Kinkley, R. Seeger and J.A. Pople, J. Chem. Phys. 72,650 (1980). doi:10.1063/1.438955

13. M. Ludwig, J. Petrzilek, J. Kulhanek and O. Pytela, Collect. Czech. Chem. Commun. 59, 391 (1994). doi:10.1135/cccc19940391

14. C.Hansch, A. Leo, and R.W. Taft, Chem. Rev. 91, 165 (1991). doi:10.1021/cr00002a004

15. A. H. Essa, B. A. Saleh, and A. J. Hameed, J. Comput. Theor. Nanosci. 6, 706 (2009). doi:10.1166/jctn.2009.1097

16 D. J. Craik, and R. T. C. Brownlee, Progress in Physical Organic Chemistry, 14, (1982).

17. j. Bromilow, R. T. C. Brownlee, D. J. Craik, P. R. Fiske, J. E. Rowe, and M. Sadek, J. Chem. Soc. Perkin Trans. II, 753 (1981).

18. S. Ehrenson, R. T. C. Brownlee and R. W. Taft, Prog. Org. Chem. 10, 1 (1973). doi:10.1002/9780470171899.ch1 